\title{
Study on the Application of Several Psychological Effects in Teaching Practice
}

\author{
Xiaodan Zhang ${ }^{1, \text { a }}$, Jianxiong $\mathrm{Li}^{2, \mathrm{~b}}$, Kai Wang ${ }^{1, \mathrm{c} *}$ \\ ${ }^{1}$ Beihua University, Jilin, China, ${ }^{2}$ Jilin administration of industry and Commerce Changyi branch \\ a z13140y@163.com, b1410770136@qq.com, c1787971787@qq.com \\ ${ }^{*}$ Corresponding author
}

Keywords: psychological effect; impact; teaching practice application; teaching efficiency

\begin{abstract}
Psychological research is associated with many fields in daily life which includes family, education, health and society, in which the psychology pedagogy is more important. It will bring a better impact on understanding, analysis, using the positive side of psychological effect and avoiding negative effect of psychological in teaching activities. This paper mainly studies the effect of seven kinds of psychological, namely, pygmalion effect / Rosenthal Effect, framing effect, the butterfly effect, symbiotic effect, recency effect, waiting effect, Aronson effect and their effects. It is advocated to follow the law of these psychological effects in the teaching practice, establish a good communication mode with students and motivate students' enthusiasm and initiative, which can effectively organize and regulate the teaching practice and improve the teaching efficiency.
\end{abstract}

\section{Introduction}

People's psychological phenomenon is gorgeous, Engels said: "It is the most beautiful flowers on earth". In the activities of human beings in the world of understanding and transformation, Human beings are never going to stop is the psychological activity. Understanding and mastering of the characteristics and laws of human being psychological activities in any field can better achieve the goal of activities. Psychological research is associated with many fields in daily life which includes family, education, health and society, in which the psychology pedagogy is more important. Education and psychology are born in the philosophy, we can also think that psychology is the theoretical basis of education, both also produced a cross disciplinary educational psychology. People seem to understand the importance of educational psychology in the study of educational theory. But in teaching practice, the substantive dialogue between pedagogy and psychology is becoming less and less.

People may think that some of the theories in psychology are difficult to be applied directly to the teaching practice. In fact, we should pay more attention to some psychological effects. Psychological effect is a regular phenomenon caused by a kind of (or many) psychological motivation in social life. It can also be said that the psychological effect is a psychological phenomenon of causal relationship and the social effect; it is some special reaction to people or things in the process of social awareness. These regular pattern special reactions will impact in relative person's action through different ways and different levels, which is crucial in the progress of action. Therefore, in teaching practice, it is very important to understand, analyze and utilize the positive aspects of the psychological effects, and avoid its negative effects. It will narrow the gap between teachers and students, give full play to the teachers' guiding role, establish good communication way, stimulate the students' enthusiasm and initiative, effectively organize and control teaching practice and improve the teaching effect. The application of seven psychological effects in teaching practice will respectively studied as follow.

\section{Pygmalion effect / Rosenthal Effect}

In fact two effects are the same principle. Pygmalion Effect is derived from ancient Greek Myths. Piga Marion, king of Cyprus, was a famous sculptor. He fells in love with a beautiful young girl who 
her carefully carved. Had Marley Weng to sculpture girl name, wearing a beautiful gown, embraced and kissed it, and sincerely hope that their love can be "girls" accept. His sincere hope that moved the goddess A Flo Siti. A Flo Siti will become a generation of sculpture has become a young girl, Marley's wife Weng beeger. Expectation and praise can produce miracles that People summed up " Pygmalion effect "from the Marley Weng' s story. In 1960, Dr. Rosenthal of Harvard University in California, who did a famous experiment in school, told the professor that in ordinary classes, assigned her to teach high IQ children for her excellent. The final results, the class score is very good which verifies the effect had Marley weng.

Popular understanding of the two effects, that is, to " Say you OK, you will do, not line ". It means, cultivate the students' self-efficacy. The accomplishment Experience is the source of self-efficacy sense. We all want to get attention, recognition and praise, so we show what happened around us like in the circle of friends or send weibo for thumb up. Adult like this, moreover who are the children of the study. Apply Pygmalion effect in the teaching practice, it will affect the students' learning effect that requires the teacher to the student consistently giving care, expectations and sincere love. In the process of the Rosenthal effect experiment, The children learn have absolute confidence in his ability, because of the teachers think that students comprehension ability will be very high, for students higher expectations, continue to focus on students' progress, and through various methods to convey to the students "you are very good" information, to produce a kind of motivation, work harder . The phenomenon has a strong reaction that the teachers' attention and expectation to the student.

\section{The Butterfly Effect}

The Butterfly Effect is a widely mentioned psychological Effect. In the $70 \mathrm{~s}$, a man named American meteorologist lorentz put forward a butterfly in the amazon rainforest occasionally wings maybe cause a tornado in Texas after two weeks. It can be interpreted the state of the future will be a huge difference as the initial conditions are very small, but after a change will enlarge unceasingly, after a long, huge chain reaction. A tiny changes can influence the development of things, indicates that the development of things is complex. In social science, the researchers think that a tiny mechanism may bring greater harm if not properly guided,; A tiny mechanism will likely produce very good result as long as the correct adjustment, appropriate guidance, and even the buzz.

As we all know, students to the teacher's cognition mainly to obey and worship in the education system,. The more younger children have stronger to the teacher. "Butterfly effect" tell us, any small words and actions may be crucial influence on the students' life. Positive and right things benefit for the students life-long; Negative and wrong things may lead to students' cognitive biases life. Of course, "butterfly effect" also has two sides in pedagogical practices. Teacher to the student of some seemingly small deviation of idea in the teaching activities need to be guide to prevent them start a prairie fire. To note here, the first is distinguish ideological bias, or just ideas; the second is not blindly to kill, but it lead to the normal track. According to the "butterfly effect", the teacher can also set up a little mechanism in the classroom teaching practice, and the appropriate adjustment, guidance, For the class effect has better development.

\section{Framing effect}

In the 2006 World Cup, Italy and France fight for the title. Results Italy won and France lost. With these words to describe the game alone, led to a quite different associations. Only said Italy victory, It reminiscent of the Italian team's efforts to win the game. It can let a person think France why will fail only said France lost the game. This is the Framing effect. In psychology, framing effect in essence is a kind of cognitive biases. It put forward first by Amos tversky and Daniel kahneman in 1981. The researchers point, though the same expectations of gain and loss in essentially, but according to the questions are presented on the surface of profit or loss, people's decision will be different. When questions pointed out the profit face, people tend to choose to evade the risk; When question points out that the loss face, people tend to choose the risk. 
Based on the framework on the front and choose conservative scheme in order to obtain good effect; in order to avoid the loss of interest selection adventures show the selection bias under the negative. the evaluation way is mainly involved that applied to the teaching practice. To express the intention of the packed in suitable framework and then presented to the students, will make it easier for students to choose according to praise and criticism to the direction of the suitable for their own plan, to receive better teaching effect. It should be selected based on the principles of several frames but commend in positive framework, criticism with negative framework. The first is that positive framework applicable to public evaluation, negative framework suitable for use in a talk in private. If you want to praise, the best public praise, the effect is better; If you want to criticism, the most appropriate private and secure, the effect will be better. The Second is that according to student's personality, to praise and criticism, the lack of a solution to breakthrough and solve problems independently can choose negative framework; positive but some aggressive can choose positive framework

\section{Symbiotic effect}

There is a kind of phenomenon in nature, a plant growth alone will appear short、drab, if with the same type of plant growth will grow exuberant. The researchers call this Symbiotic effect that the phenomenon of mutual promotion in the plant kingdom. In fact, the effect of "symbiotic" is also widely appeared in human society. From 1901 to 1982, it is an outstanding symbiotic typical has appeared 25 Nobel Prize winners at the Kaldi laboratory in the UK. The Jewish Scriptures in the Talmud has a famous saying: live with wolves, you can only learn to howl; Contact with those good people, you will be good effect. So in the social, people hope more to work with the best people, join more outstanding team, let oneself in a high starting point and positive competition atmosphere of growth.

Symbiotic effect is already widely used in teaching practice. The most common form embodiment is "support group", in the older generation there we also heard " Help each other make progress". Symbiotic effect can be widely used in every stage of the teaching practice. In the primary stage, teachers use of "symbiotic" organization set up support groups, help students find benchmarking, close the students on their living, help each other. In institutions of higher learning, teachers' use of "symbiotic" both in organizing group and interest groups can integrate everyone's thinking, knowledge with each other on different points. Especially in polytechnic colleges all be gathered together, as a result of knowledge structure, technical expertise, way of thinking and scientific research level and so on, we learn from each other and study each other and influence each other, make thinking to complement each other, constantly improve the innovation ability, More scientific research achievements and enhance learning effect.

\section{Recency effect}

A.Ladins (1957) studied the phenomenon of the first Primacy Effect), which indicated different internal sequence are used to express the same information to the outside world, the resulting cognitive feedbacks are completely different. The first appearing information has a greater impact on the relative people. But if some activities between two expression text are interspersed, such as reading the text, do the math, etc., most people will get information after activities. This phenomenon is called recency effect. For example, the description of a person, the first warm words, after the emergence of a cold word, people of 78\% think this person is friendly. And if the text is open to the end of a campaign, the result is just the opposite. Generally the psychologically open the recency effect produced obvious effect; and psychological has a stable tendency, first effect produces the effect of significantly.

In teaching practice, recency effect and primacy effect play subtle roles. According to recency effect theory, people memorize things, the memory effect of the final part is better than that of the middle part, especially memory of the most knowledge points are decided by last impression 
stimulation. Therefore, it is important to point out that the key points in the end of the classroom activities, or the points of knowledge to be learned and learned are stressed on both ends of the classroom activities. Information the time interval of knowledge is longer, the effect is more obvious. Therefore, if a knowledge interpretation needs a long time, be sure to summarize after knowledge or practice.

\section{Wait effect}

Waiting effect is the change in attitude, behavior and other aspects of people waiting for something. This kind of psychological effect in the enterprise management and control is often used by excellent managers who revealed some new tasks in advance, stimulate the expectations of the employees for a new task and form wait effect, so that the staff interest and attitude toward the positive direction.

In teaching activities, this phenomenon is not applied too much, but some excellent teachers have tried to use the waiting effect. They will introduce some new key knowledge in advance, which will enable students produce wait psychological to the new unit, promote positive changes in the student's learning interest and attitude. However, one thing to note is that the wait created by suspense can bring certain effect. But the suspense is good or bad as well as the timing of suspense, which will have strong influence in the size of wait effect, even a lot of positive and negative effects. That is, in the teaching practice, the choice of knowledge points can be used to wait for effect and at what point in time to set the suspense are essential.Need to pay attention to the following several points, suspense time should not be too long, if it is too long that will reduce students' learning interest and enthusiasm, and even lead to counterproductive. In giving suspense, several questions should be convenient for students to answer, so that it can be more to stimulate students' interest, let them to think actively. the third is to inform the students waiting to achieve what kind of purpose. Therefore, school teachers in teaching practice should use wait effect in the choice of the most need the knowledge point, and the best time to use.

\section{Aronson effect}

A parked old car behind a dormitory building, in every evening, the children climbed car crowhop and made a sharp thud. Adults try their best to prevent these, but all were unsuccessful. The more prevention, the children play with the happier. There was a person who thought of the way, let the children who play the game. First day, jumping the loudest award toy pistol; the next day, the prize for two toffee; on the third day, prizes for two peanuts. Results on the third day, the children jumped off the car, said not to jump, there was no meaning. That's settled. With the reduction of reward that leads to attitude became more negative, with the increase of the reward that leads to mental gradually positive attitude, this phenomenon in social psychology is known as the "Aronson effect". According to Aronson effect, people like the people or things that continue to reward and praised themselves, do not like to decrease. In the process of childhood or primary school teaching, the " direct education is hard to accept" situation, the use of "reward decline law" can play a wonderful psychological effect.

Especially in the evaluation of students, if there is more need to praise, the best way is to separate praise, compared to one time effect of praise, respectively, repeatedly, gradually increasing the strength of praise can increase the confidence of the students and learning motivation. If some criticisms are need, one time conducted is better. Not only because the problems need to be resolved as soon as possible, but also because it can reduce bruising students' Self-esteem.

\section{Summary}

The application of psychological effect is very important, Educational practice not only pass knowledge, but also promote students to form a healthy and independent personality. At the same 
time, the use of psychological effect in teaching activities can be better for communication between teacher and students, and help to regulate the teaching process, improve the teaching effect.

\section{References}

[1] Lei Ming. Construction of psychological health education psychology: Connotation, research object and discipline system[J]. Journal of Sichuan University of Science and Engineering (SOCIAL SCIENCE EDITION), 2014,03:31-42.

[2] Shi Yingling,He Yongxiu. Investigation and analysis of psychological effect in University Classroom Teaching[J], China Electric Power Education,2011,05:45-46.

[3] Deng Muhui. Some psychological effects on education and teaching[J]. D Journal of Chinese language teaching and learning (Academic Journal) ,2011,03:22-25.

[4] Wany Yan. The application of educational psychology in the teaching of students' Education[J]. Modern communication,2011,09:197-198.

[5] Wang Keyin. Effect of psychological effect on teaching effect [J]. Journal of changchun university of science and technology2010,12:185-186.

[6] Luo Denghong,Wu Shouwei. The essence, theoretical basis and research methodology of teaching art -- the relationship between pedagogy and psychology [J].Journal of Nanjing Normal University (SOCIAL SCIENCE EDITION), 2012,02:78-82.

[7] Liu Zhongqiong, Applying the common psychological effect to optimize the teaching effect [J]. Education Teaching Forum, 2012,39:150-151. 